\title{
NOVAS SINONIMIAS E NOVOS TÁXONS EM CERAMBYCIDAE (COLEOPTERA) NEOTROPICAIS
}

\author{
Ubirajara R. Martins ${ }^{1}$ \\ Maria Helena M. Galileo ${ }^{2}$
}

\begin{abstract}
New SYNonyms AND NEW taxa IN NeOtropical Cerambycidae (COLEOPTERA). New synonym proposed: Tachocha Lane, $1970=$ Phoebemima Tippmann, 1960 (Hemilophini). New taxa described: Apanoeme castanea sp.n. from Brazil, Mato Grosso do Sul (Oemini); Lissoeme maculata, sp.n. from Brazil, Bahia (Achrysonini); Taygayba gen.n., type species $T$. venezuelensis sp.n. from Venezuela (Hesperophanini ?); Neocompsa santarensis sp.n. from Brazil, Pará (Ibidionini); Hippopsis campaneri sp.n. from Brazil, Goiás (Agapanthiini); Iquiara gen.n., type species I. tuiuca sp.n. from Ecuador (Hemilophini); Paracallia gen.n., type species $P$. bonaldoi sp.n. from Brazil, Acre (Calliini); Neopibanga gen.n., type species, N. brescoviti sp.n. from Brazil, Rondônia (Eupromerini).

KEY WORDS. Coleoptera, Cerambycidae, Cerambycinae, Lamiinae, Neotropical
\end{abstract}

Esta contribuição consiste de nota sinonímica e das descrições de novos táxons em Cerambycidae neotropicais.

As siglas citadas correspondem: CMNH - Carnegie Museum of Natural History, Pittsburgh; IZAV - Instituto de Zoologia Agrícola, Universidad Central de Venezuela, Maracay; MAGD - Museum and Art Gallery, Doncaster; MCNZ Museu de Ciências Naturais, Fundação Zoobotânica do Rio Grande do Sul, Porto Alegre; MNRJ - Museu Nacional, Universidade Federal do Rio de Janeiro, Rio de Janeiro; MZSP - Museu de Zoologia, Universidade de São Paulo, São Paulo; MNHN - Muséum National d'Histoire Naturelle, Paris; NRMS - Naturhistoriska Riksmuseum, Estocolmo.

\section{Oemini \\ Apanoeme castanea sp.n.}

Fig. 1

Colorido geral castanho-escuro, os élitros um pouco mais claros. Face superior da cabeça fina e densamente pontuada. Lobos superiores dos olhos mais distantes entre si que a largura de um lobo. Antenas atingem o ápice dos élitros aproximadamente no meio do artículo VII. Escapo subcilíndrico, pouco e gradual-

1) Museu de Zoologia, Universidade de São Paulo. Caixa Postal 42694, 04299-970 São Paulo, São Paulo, Brasil. Pesquisador do CNPq.

2) Museu de Ciências Naturais, Fundação Zoobotânica do Rio Grande do Sul. Caixa Postal 1188, 90001-970 Porto Alegre, Rio Grande do Sul, Brasil. Pesquisadora do CNPq. 
mente engrossado para a extremidade, artículos III e IV subiguais. Asperezas nos artículos basais muito discretas. Protórax mais longo do que largo, arredondado aos lados, com constrição basal evidente. Pronoto convexo; superfície densamente granulosa ao longo do meio, com granulação pouco mais esparsa nos lados. Partes laterais do protórax e prosterno com pontuação semelhante. Processos pro- e mesosternal ausentes. Elitros pontuados em toda superfície; pêlos amarelados, curtos, sem pêlos pretos entremeados. Extremidades elitrais acuminadas. Profêmures fusiformes. Meso- e metafêmures ligeiramente engrossados para a extremidade. Metatíbias mais longas do que os metafêmures. Metatarsômero I curto, tão longo quanto II+III.

Dimensões em milímetros. Comprimento total 14,8; comprimento do protó$\operatorname{rax} 2,8$; maior largura do protórax 2,5; comprimento elitral 10,5; largura umeral 2,7.

Material-tipo. Holótipo macho, BRASIL, Mato Grosso do Sul: Três Lagoas (Horto Barra do Moeda, Três Lagoas Agroflorestal, "transition cerrado-Eucaliptus grandis stand, ethanol trap"), 9.XI.1993, C. A. Flechtmann leg. (MZSP).

Discussão. Apanoeme castanea é a segunda espécie descrita no gênero; difere de A. amazonica: pelo colorido acastanhado uniforme; pelos lobos oculares superiores separados entre si por distância subigual à largura de um lobo; pelas antenas com asperezas discretas e pelo protórax mais longo do que largo. Em $A$. amazonica os élitros a as pernas são bicolores; os lobos oculares superiores são separados por distância menor do que a largura de um lobo; as antenas têm asperezas muito desenvolvidas e o protórax é mais largo do que longo.

\section{Achrysonini}

\section{Lissoeme maculata sp.n.}

Fig. 2

Colorido geral vermelho-alaranjado a alaranjado; escapo avermelhado; pedicelo, flagelômeros, pedúnculo dos fêmures, tíbias e tarsos, pretos; centro dos élitros com uma grande mancha escura com reflexos azulados (pode desaparecer completamente). Palpos maxilares mais longos que os labiais. Cabeça grosseiramente pontuada. Tubérculos anteníferos subaguçados. Escapo mais curto que metade do artículo III; superfície rugosa. Franja de pêlos nos flagelômeros basais moderadamente densa. Protórax mais longo do que largo, um pouco constrito na base; pronoto opaco. Processo prosternal estreito, com lados levemente alargados para a ápice. Processo mesosternal mais largo que uma mesocoxa com ápice truncado. Élitros pontuados; extremidades levemente emarginadas, com espículo no ângulo externo; cerdas curtas em toda a superfície. Fêmures pedunculados e longamente clavados. Tíbias não carenadas. Primeiro artículo dos metatarsos tão longo quanto II-V.

Dimensões em milimetros, respectivamente macho/fêmea. Comprimento total, 9,5-14,4/9,3-14,7; comprimento do protórax, 2,4-3,6/1,8-3,0; maior largura do protórax, 1,7-2,4/1,4-3,1; comprimento do élitro, 6,5-9,4/6,5-10,9; largura umeral, 2,0-2,8/1,9-3,4.

Material-tipo. Holótipo macho, BrASIL, Bahia: Encruzilhada (Motel da 

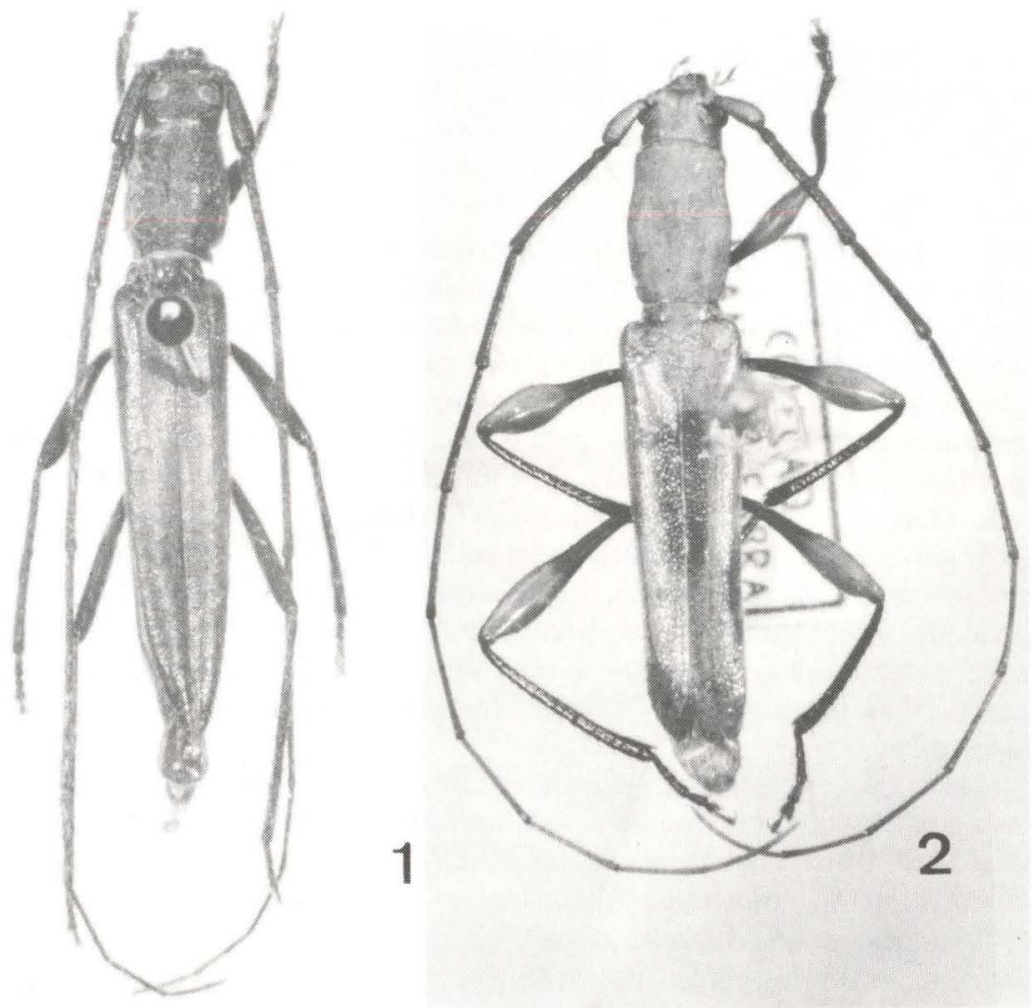

Figs 1-2. (1) Apanoeme castanea sp.n., holótipo macho; (2), Lissoeme maculata sp.n., holótipo macho.

Divisa, 960 m, estrada Rio-Bahia km 965), XI.1973, Seabra \& Roppa leg. (MNRJ). Parátipos-mesmos dados e coletores do holótipo: macho, X.1971 (MCNZ); macho, X.1972 (MNRJ); fêmea, XI.1972 (MNRJ); macho, XII.1972 (MNRJ); fêmea, XI.1974 (MNRJ); 3 macho, 8 fềmeas, XII. 1974 (macho, 6 fềmeas, MNRJ; 2 macho, 2 fêmeas MZSP).

Discussão. Distingue-se de Lissoeme testacea Martins, Chemsak \& Linsley, 1966 pela presença de mancha escura nos élitros (quando presente) e pelo colorido preto das antenas, base dos fêmures, tíbias e tarsos. Além disso, L. testacea é conhecida da Venezuela, enquanto L. maculata é procedente do sul da Bahia, Brasil.

\section{Hesperophanini ?}

\section{Taygayba gen.n.}

Etimologia. Tupi, taygayba $=$ valente.

Espécie-tipo, Taygayba venezuelensis sp.n.

Tubérculos anteníferos projetados. Genas agudas. Lobos oculares superiores com oito fileiras de omatídios; distância entre os lobos, dorsalmente, igual ao triplo 
da largura de um lobo. Lobos oculares inferiores ocupam quase todo lado da cabeça. Antenas com onze artículos. Antenas (macho) ultrapassam o ápice elitral a partir da metade do antenômero VIII; das fêmeas a partir do X. Escapo curto, com sulco na metade basal do lado superior. Artículo III (macho) não carenado, com 1,5 vezes o comprimento do escapo; subigual ao IV; demais artículos com comprimento gradualmente crescente; artículo XI curvo na região apical. Nas fêmeas, escapo com sulco raso na base; artículo III o mais longo; demais artículos com comprimentos gradualmente decrescentes. Protórax (macho) mais largo do que longo, arredondado aos lados; pronoto com dois tubérculos pretos, glabros, pouco à frente do meio; nos tubérculos inicia-se um sulco curvo, que atinge a margem basal; no meio uma pequena área glabra; de cada lado, para o lado externo dos sulcos, uma pequena fóvea. Processo prosternal truncado, com tubérculo. Protórax (fêmea) com lados muito levemente projetados ao nível do meio. Pronoto com tubérculos pontiagudos, muito desenvolvidos, pretos, glabros; sem sulco, sem área central glabra e sem as fóveas laterais. Élitros pubescentes, exceto sobre as manchas ebúrneas; extremidade arredondadas em conjunto. Cavidade coxal anterior levemente angulosa. Fêmures lineares; extremidades dos meso- e metafêmures com abas apicais, às vezes, aguçadas. Tíbias não carenadas. Abdômen com cinco urosternitos visíveis, o último sub-retangular.

Discussão. A presença de manchas ebúrneas nos élitros que são pubescentes em toda a extensão, a presença de tubérculos no pronoto, os fêmures lineares e os processos pro- e mesosternal com superfície articular lateral situariam o gênero em Eburiini, entretanto o protórax é desarmado aos lados.

Este gênero, embora semelhante a Coccoderus Buquet, 1840 não pode ser enquadrado em Botriospilina (Torneutini) por apresentar antenas com onze artículos, élitros pubescentes e ausência de escova no esternito VIII das fềmeas.

Embora a posição deva ser reestudada o gênero, provisoriamente, é enquadrado em Hesperophanini.

\section{Taygayba venezuelensis sp.n.}

Fig. 3

Macho. Colorido geral alaranjado. Cada élitro com três manchas subcirculares ebúrneas, uma na base, uma pouco à frente do meio, uma no terço apical. Cabeça, protórax e élitros densa e uniformemente pubescentes; antenas com franja de pêlos longos, densos, mais evidentes nas fêmeas. Protórax (macho) com pontuação sexual: pontos finos e densos; (fêmea) com pontos mais profundos e separados entre si.

Dimensões em milímetros, respectivamente macho/fêmea. Comprimento total, 34,0-40,0/38,0-43,0; comprimento do protórax, 6,4-7,2/6,2-6,9; maior largura do protórax, 7,9-9,3/7,2-8,8; comprimento do élitro, 27,0-29,0/30,0-34,5; largura umeral, 9,3-11,0/11,2-13,3.

Material-tipo. Holótipo macho, Venezuela, Aragua: Maracay (Rancho Grande, 1100 m), 28.III.1967, F. Fernandez \& C.J. Rosales leg. (IZAV). Parátipos - macho, Caracas, ex-coll. A. Sallé (MNHN); fêmea, Aragua: Maracay (Rancho Grande), 20.V.1971, F. Fernandez leg. (MZSP); fêmea, Las Tricheras (MAGD). 


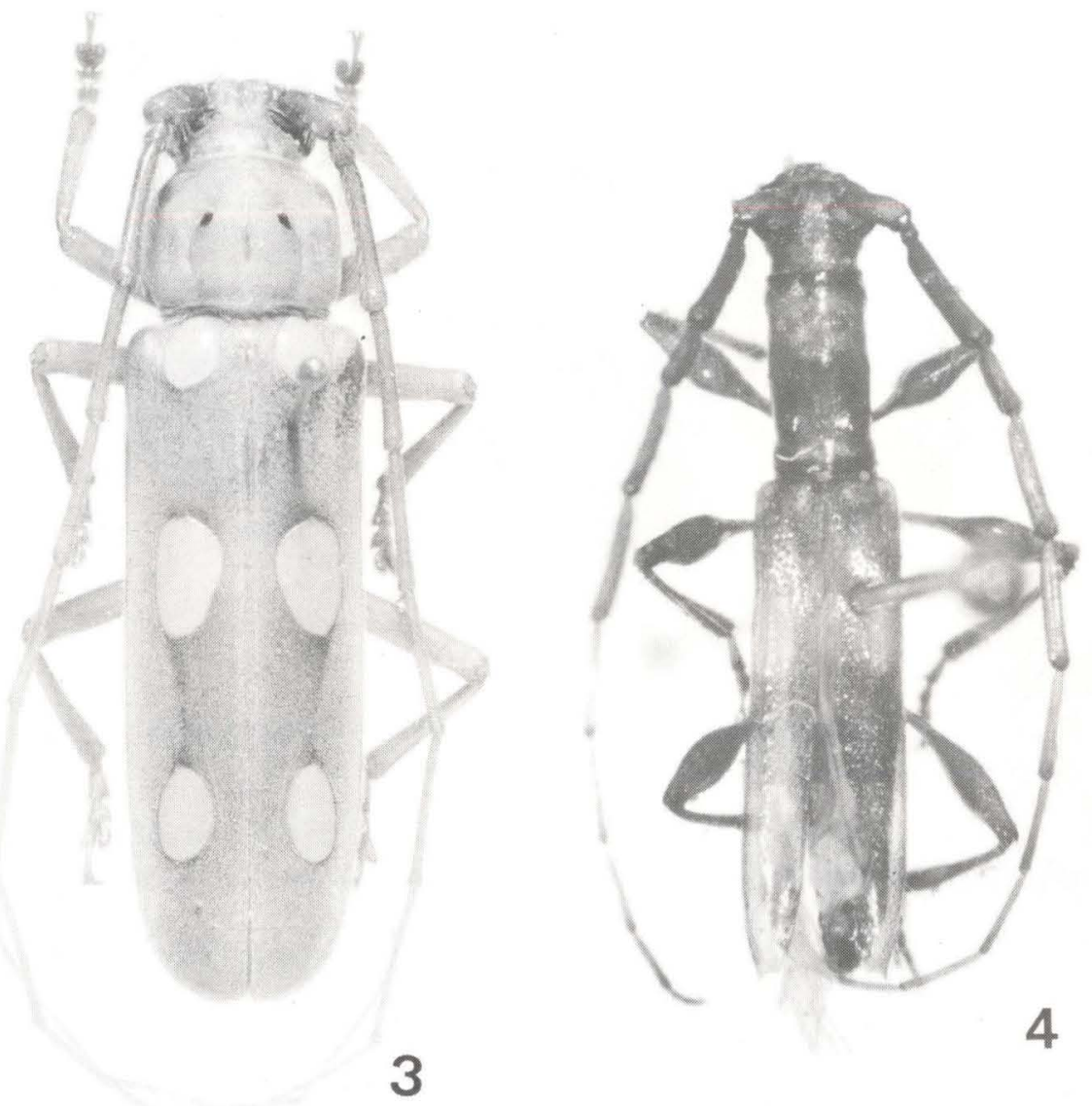

Figs 3-4. (3) Taygayba venezuelensis sp.n., holótipo macho; (4) Neocompsa santarensis sp.n., holótipo macho.

\section{Ibidionini}

\section{Neocompsa santarensis sp.n.}

Fig. 4

Macho. Tegumento avermelhado; cada élitro com duas manchas amareladas: uma longitudinal no terço anterior, outra arredondada no quarto apical. Antenas com os artículos III-VI engrossados, carenados. Protórax todo coberto pela pubescência serícea que é esparsa. Pronoto sem tubérculos. Prosterno com pubescência serícea no terço posterior. Élitros com pubescência serícea esparsa na metade apical; mancha anterior sem costa; extremidade ligeiramente emarginada, com ângulo externo espinhoso; o espinho curto. Fêmures pedunculados e clavados; carenados perto do ápice. Metasterno coberto por pubecência. 

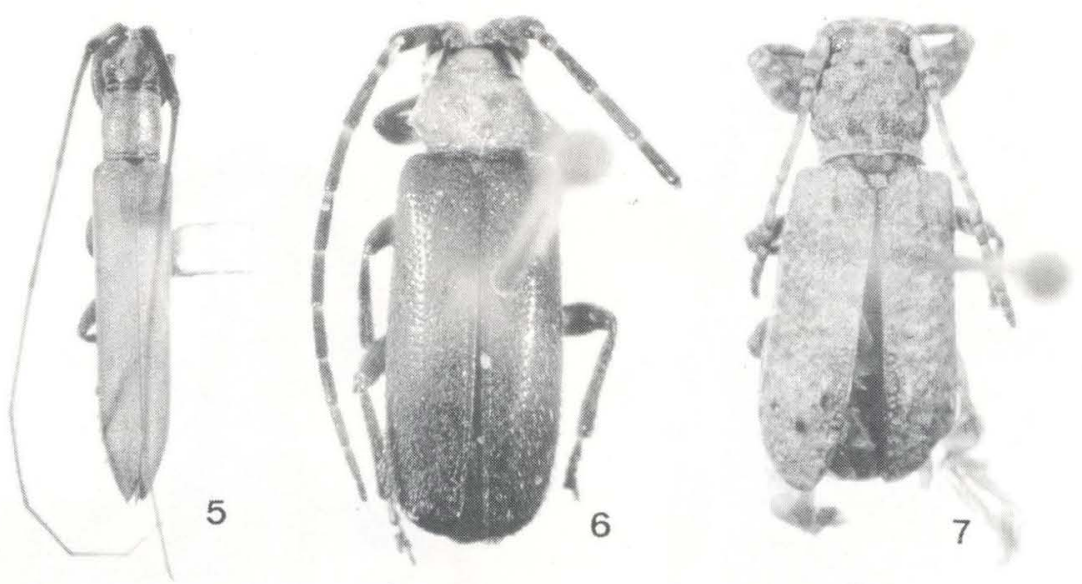

Figs 5-7. (5) Hippopsis campanerisp.n., holótipo macho; (6) Paracallia bonaldoisp.n., holótipo macho; (7) Neopibanga brescoviti sp.n., holótipo macho.

Dimensões em milímetros. Comprimento total, 9,3; comprimento do protórax, 2,4; maior largura do protórax, 1,2; comprimento do élitro, 5,7; largura umeral, 1,8 .

Material-tipo. Holótipo macho, BRASIL, Pará: Santarém (Fátima de Uricurituba), 24.I.1994, A. Brescovit leg. (MZSP).

Discussão. Neocompsa santarensis tem uma pubescência elitral característica; a metade anterior dos élitros é glabra e a metade apical esparsamente pubescente. Duas espécies apresentam a região umeral desnuda, $N$. tuberosa Martins e $N$. alacris (Bates); neste caso a pubescência não recobre os úmeros, mas está presente junto à sutura. Além disso as duas espécies têm distribuição muito diversa: N. alacris no México e em El Salvador, $N$. tuberosa na Costa Rica, Panamá e Colômbia.

\section{Agapanthiini}

\section{Hippopsis campaneri sp.n.}

Fig. 5

Pertence ao grupo solangeae (GALILEO \& MARTINS 1988).

Tegumento castanho-avermelhado mais claro no dorso dos élitros e na metade apical dos profêmures; revestido por pubescência esbranquiçada, uniformente distribuída, que não constitui faixas longitudinais. São glabros: duas áreas semicirculares junto à margem anterior do mesosterno; o tubérculo do metasterno e a borda apical dos urosternitos. Fronte muito estreita, mais longa do que larga. Lobos superiores dos olhos mais aproximados entre si do que a largura de um lobo. Antenas atingem a ponta dos élitros no ápice do antenômero $\mathrm{V}$, com franja de pêlos 
curtos no lado interno. Protórax sem faixas de pubescência mais clara, com pilosidade esbranquiçada, uniforme, não muito densa. Processo mesosternal plano, com pilosidade densa, amarelada, na ponta. Metasterno com tubérculo transversal, desenvolvido, ao nível do terço basal. Élitros sem faixas de pubescência serícea; pontuação e pubescência uniformes; ápices de per si acuminados. Primeiro urosternito com depressão semelhante a de Hippopsis tuberculata (GALILEO \& MARTINS 1988: 181, Fig. 4), ultrapassa o meio, mas termina distante da margem posterior; porção posterior do orifício carenada; região anterior com bordas guarnecidas de pêlos curtos. Metatrocanteres pilosos. Metafêmures engrossados na base, pilosos na margem inferior; na parte interna da base deprimida e com tegumento rugoso.

Dimensões em milímetros. Comprimento total, 9,7; comprimento do protórax , 1,5; maior largura do protórax, 1,3; comprimento do élitro, 6,9; largura umeral, 1,7 .

Material-tipo. Holótipo macho, BRAsiL, Goiás: Colinas do Sul (Serra da

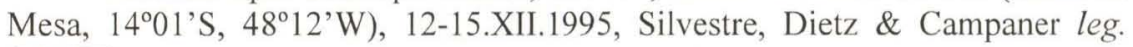
(MZSP).

Discussão. Pela forma da depressão do primeiro urosternito e pela presença de tubérculo no metasterno, Hippopsis campaneri assemelha-se a $H$. tuberculata Galileo \& Martins, 1988. Difere principalmente pela pubescência corporal que não constitui faixas longitudinais, mas está uniformemente distribuída. Em H. tuberculata a cabeça, o protórax e os élitros apresentam faixas longitudinais de pubescência.

\section{Hemilophini}

\section{Phoebemima Tippmann, 1960}

Phoebenima Tippmann, 1960: 205; Monné, 1995: 36 (cat.).

Tacocha Lane, 1970: 399; Galileo \& Martins, 1996: 233 (revisão). Syn.n.

Recentemente recebemos para exame, enviado pelo colega M.A. Monné (MNRJ), um exemplar de $P$. ensifera Tippmann, 1960, espécie-tipo de Phoebemima. Tal como o holótipo (examinado o diapositivo), o exemplar encontra-se em mau estado de conservação, impossibilitando a verificação da existência de manchas de pubescência branca, compacta, nos élitros. Apesar disso, é possível confirmar a suposição de GALILEO \& MARTINS (1996) a respeito da sinonímia entre Phoebemima e Tacocha.

O gênero Phobemima fica com a seguinte composição:

\section{P. aequatoria (Lane, 1970: 399), comb.n.}

Tacocha aequatoria; Galileo \& Martins, 1996: 234, Fig. 2. -Equador.

2. P. antiqua (Gahan, 1889: 399), comb.n.

Tacocha antiqua; Galileo \& Martins, 1996: 234, Fig. 3. - Brasil (Rio de Janeiro).

3. P. ensifera Tippmann, 1960: 206, est. 13, Fig. 32a. - Bolívia.

4. P. teteia (Galileo \& Martins, 1996: 236, Fig. 4), comb.n. - Brasil (Rondônia).

5. P. teaphia (Bates, 1881: 199), comb.n.

Tacocha teaphia; Galileo \& Martins, 1996: 234, Fig. 1. - Equador, Brasil (Amazonas, Mato Grosso). 


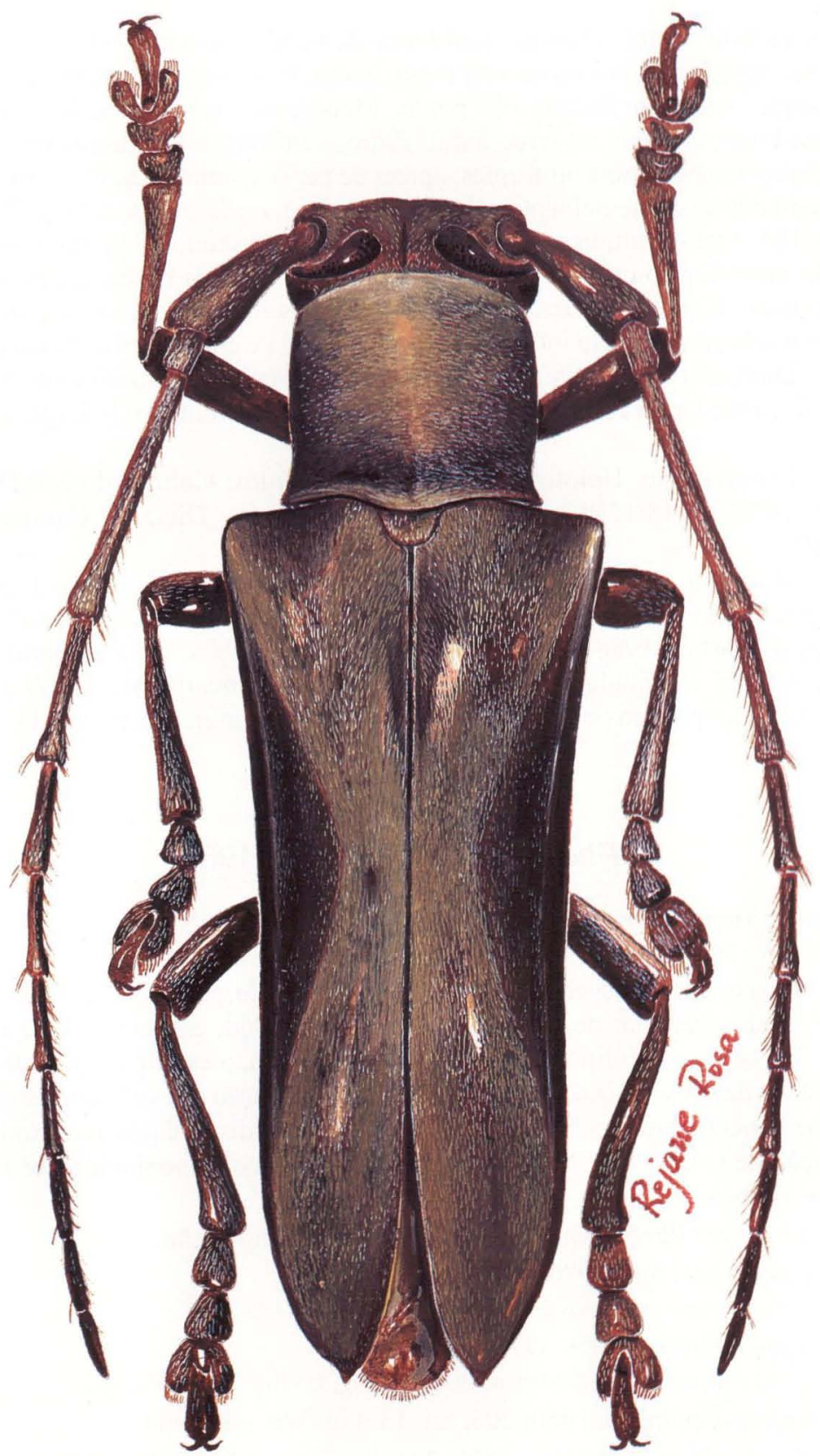

Fig. 8. Iquiara tuiuca sp.n., holótipo macho.

Revta bras. Zool. 15 (1): 47 - 58, 1998 


\section{lquiara gen.n.}

Etimologia. Tupi; iquiara = gordo, alusivo ao aspecto corporal compacto. Espécie-tipo, Iquiara tuiuca sp.n.

Aspecto geral robusto. Fronte com mais do que o dobro do diâmetro do escapo. Lobos oculares superiores largos tão distantes entre si quanto a largura de um lobo; lobos inferiores com mais do que o dobro do comprimento das genas; ligação entre os lobos pelo menos com quatro fileiras de omatídeos. Antenas (macho) atingem o ápice na extremidade do antenômero X; antenômero III com quase o dobro do comprimento do escapo; flagelômeros não espessados. Protórax quase tão longo quanto largo; lados subparalelos, sem projeções. Élitros sem pontos contrastantes, desprovidos de pontos concentrados na base; sem manchas de pubescência branca compacta; extremidades prolongadas em espinho curto. Metafêmures tão longos quanto os mesofêmures, atingem a borda apical do urosternito II. Metatarsômero I mais curto que II+III. Meso- e metatarsos I e II intumescidos. Apêndice interno das unhas mais longo que os externos. Último urotergito sem projeções laterais.

\section{lquiara tuiuca sp.n.}

Fig. 8

Etimologia. Do Tupi, tuiúca $=$ barro, alusivo a cor do tegumento corporal.

Macho. Tegumento castanho-avermelhado. Pubescência amarelo-esbranquiçada reveste: região post-ocular, protórax, face ventral do corpo e os élitros, exceto larga área lateral, triangular, que não alcança a sutura. Escapo, pedicelo e ápice dos flagelômeros acastanhados. Manchas de pubescência amarelada, compacta, nos lados da metade anterior do metasterno e nos lados dos urosternitos I-IV. Fronte e pronoto com pontos grossos, próximos. Élitros com pontos mais finos e esparsos, gradualmente menores em direção ao ápice.

Dimensões em milímetros. Comprimento total, 22,3; largura umeral, 6,8.

Material tipo. EQUADOR. Pichincha: Tinalandia (route Quito-Santo Domingo, $650 \mathrm{~m}$ ), holótipo macho, 17.II.1980, Porion-Bertrand leg. (MNRJ).

Discussão. Semelhante a Butocrysa Thomson pelo padrão de colorido e aspecto corporal. Difere pelo protórax tão largo na margem anterior como na posterior, base elitral sem crista, úmeros inermes, ápice dos élitros com espículo apical e antenas (macho) apenas ultrapassam a extremidade do corpo. Em Butocrysa o protórax é mais largo anteriormente do que na base, os élitros têm crista centrobasal, úmeros com tubérculo e ápice obliquamente truncado; as antenas (fềmea) ultrapassam o ápice dos élitros com aproximadamente três artículos.

Chegamos a aventar a hipótese desta espécie ser Adesmus brunneus Aurivillius, 1923, que foi descrita com base em pelo menos dois exemplares cujo sexo foi indicado como "macho ?", procedentes do Vale do Cauca, Colômbia e depositados no NRMS. Moure fotografou o holótipo em vistas dorsal e lateral, exemplar glabro na face dorsal, provavelmente com a pubescência inteiramente destruída. Iquiara tuiuca difere principalmente pelo aspecto geral mais robusto e pela ausência de carenas nos élitros. 


\section{Calliini \\ Paracallia gen.n.}

\section{Espécie-tipo, Paracallia bonaldoi sp.n.}

Fronte tão longa quanto larga. Olhos finamente facetados; lobos oculares superiores com 7 fileiras de omatídios, tão distantes entre si quanto o dobro da largura de um lobo; lobos oculares inferiores pouco mais curtos do que as genas. Tubérculos anteníferos não projetados, distantes. Antenas mais curtas do que o corpo; flagelômeros cilíndricos, ligeiramente intumescidos. Escapo sem cicatriz, tão longo quanto o antenômero III; comprimento do IV em diante gradativamente decrescente; pêlos muito esparsos no lado interno dos flagelômeros. Protórax mais largo do que longo; espinho manifesto ao nível do terço posterior. Pronoto com cinco tubérculos: dois ântero-laterais, um centro-posterior e dois ao lado do central, pouco indicados. Processos esternais sem tubérculos. Élitros levemente deprimidos ao longo da sutura, sem carenas, com setas curtas abundantes; declividade lateral sem franja de pêlos; ápice elitral arredondado em conjunto. Metafêmures subfusiformes. Mesotíbias sulcadas ao nível do meio. Metatarsômero I tão longo quanto o II+III.

Discussão. Na chave para os gêneros apresentada por GALILEO \& MARTINS (1991), Paracallia situa-se no dilema 30, pelo escapo sem cicatriz; pela presença de setas elitrais; pela região centro-basal dos élitros desprovida de depressão com grânulos e pelo dente interno das garras tarsais desenvolvido. Lustrocomus, descrito recentemente (MARTINS \& GALILEO no prelo), também situa-se nesse dilema.

Paracallia assemelha-se a Anapsicomus e Lustrocomus, mas o aspecto geral não é "lampiróide" e o disco pronotal apresenta cinco tubérculos. Assemelha-se a Callia, mas difere pelos artículos antenais mais intumescidos, pelos lobos oculares inferiores mais curtos do que as genas; pelos espinhos laterais do protórax mais desenvolvidos e situados ao nível do terço posterior e pelo pronoto com cinco tubérculos.

\section{Paracallia bonaldoi sp.n.}

Fig. 6

Etimologia. A espécie é dedicada ao seu coletor o aracnólogo Alexandre B. Bonaldo (MCNZ).

Macho. Cabeça vermelha com grande mancha preta atrás dos olhos e tubérculos anteníferos, pretos. Antenas pretas exceto: região basal do lado interno do escapo; anel basal do pedicelo e dos flagelômeros III-X. Protórax vermelho exceto proepimeros. Élitros, face ventral, metade apical dos fêmures, tíbias e tarsos, pretos. Metade basal dos fêmures amarelo-avermelhada. Cabeça com pubescência branca, esparsa, exceto sobre as áreas de tegumento escuro onde é brilhante, sem pontuação. Antenas pubescentes, com franja interna de pêlos muito esparsos. Pronoto com cinco tubérculos e pubescência branca, esparsa, nas depressões. Élitros densamente pilosos; os pêlos curtos e densos; pubescência acastanhada em toda a superfície. Pernas pilosas. Face ventral com pubescência esbranquiçada, densa. 
Dimensões em milímetros. Comprimento total, 7,3; comprimento do protórax, 1,2; maior largura do protórax, 2,2; comprimento do élitro, 5,3; largura umeral, 2,3 .

Material-tipo. Holótipo macho, BRASIL, Acre: Xapurí (Pimenteira), 6.IV.1956, A. Bonaldo leg. (MCNZ).

\section{Eupromerini}

\section{Neopibanga gen.n.}

\section{Espécie tipo, Neopibanga brescoviti sp.n.}

Olhos divididos; lobos oculares superiores, com seis fileiras de omatídios; mais distantes entre si do que a largura de um lobo. Antenas com onze artículos. Escapo tronco-cônico; pedicelo tão longo quanto o antenômero XI. Protórax com dois pincéis de pêlos pretos, curtos sobre a borda anterior; disco pronotal com três tubérculos: dois anteriores e um central. Escutelo quadrangular. Élitros com um tubérculo centro-basal pouco pronunciado; três tubérculos pequenos à frente da declividade apical correspondentes a TDI e TDII (Tubérculo dorsal I e II de GALILEO \& MARTINS 1995) e um adicional, entre eles, situado posteriormente, cobertos por tufos de pêlos curtos; tubérculo central ausente; carenas indistintas: uma da base até o tubérculo centro-posterior e outra, mais lateral, do úmero até quase o ápice. Parte anterior do metasterno com tubérculo arredondado, evidente. Pernas como em Eupromera Westwood, 1846.

Discussão. O gênero difere de todos os demais gêneros de Eupromerini pela seguinte combinação de caracteres: margem anterior do pronoto com dois tufos de pêlos; metasterno com tubérculo; élitros com um tubérculo centro-basal e três tubérculos dorsais à frente da declividade apical.

\section{Neopibanga brescoviti sp.n.}

Fig. 7

Etimologia. O epiteto é uma homenagem ao coletor da espécie, aracnólogo Antonio A. Brescovit, Instituto Butantan, São Paulo.

Tegumento castanho-avermelhado coberto por pêlos escamiformes amarelados entremeados de pêlos brancos. Lado interno dos lobos inferiores dos olhos com uma sensila evidente. Antenas atingem o meio dos élitros; antenômeros III e IV com dois anéis escuros; demais artículos escurecidos no ápice. Protórax, na margem anterior, com dois tufos de pêlos pretos. Tubérculos elitrais com tufos de pêlos pretos. Tubérculo e lados do metasterno pontuados. Tegumento das pernas com áreas escuras. Último urosternito com a região centro-apical deprimida.

Dimensões em milímetros, Comprimento total 5,5-6,6; comprimento do protórax 1,0-1,3; maior largura do protórax 1,3-1,7; comprimento do élitro 3,8-4,6; largura umeral 1,7-2,2. 
Material-tipo. Holótipo macho, Brasil, Rondônia: Porto Velho, 15.IV.1996, A. Brecovit leg. (MCNZ); parátipo macho, mesmos dados do holótipo (MZSP).

\section{REFERÊNCIAS BIBLIOGRÁFICAS}

BAtes, H.W. 1881. Notes on longicorn Coleoptera. Revision of the Aérenicides and Amphionychides of tropical America. Ann. Mag. Nat. Hist., London, 8 (5): 196-204.

GAHAN, C.J. 1889. On new lamiidae Coleoptera in the British Museum collection. Ann. Mag. Nat. Hist., London, 3 (6): 387-400.

GALILEO, M.H.M. \& U.R. MARTINS. 1988. Notas sobre Agapanthiini (Coleoptera, Cerambycidae, Lamiinae). I. Hippopsis do grupo solangeae. Revta bras. Ent., São Paulo, 32 (2): 179-185.

1991. Revisão da tribo Calliini (Coleoptera, Cerambycidae, Lamiinae).

G. it. Ent., Cremona, 5: 243-262.

1995. Revisão da tribo Eupromerini, trib.n. (Coleoptera, Cerambycidae, Lamiinae) da região Neotropical. Revta bras. Ent., São Paulo, 39 (1): 131-150.

- 1996. Revisão do gênero Tacocha Lane, 1970 (Coleoptera, Cerambycidae, Lamiinae, Hemilophini). Revta bras. Ent., São Paulo, 40 (2): 233-236.

LANE, F. 1970. Cerambycoidea neotropica nova VII. Stud. ent., Petrópolis, 13 (1/4): 369-428.

MARTINS, U.R. \& M.H.M. GALILEO. 1996. Descrições e notas sobre Cerambycidae (Coleoptera) sul-americanos. Revta bras. Zool., Curitiba, 13 (2): 241-311.

MonNÉ, M.A. 1995. Catalogue of the Cerambycidae (Coleoptera) of the Western Hemisphere. Part XI. São Paulo, Sociedade Brasileira de Entomologia, $157 \mathrm{p}$.

1995. Catalogue of the Cerambycidae (Coleoptera) of the Western Hemisphere. Part XX. São Paulo, Sociedade Brasileira de Entomologia, 120p. TipPMANN, F.F. 1960. Studien üeber neotropische Longicarnier I (Coleoptera, Cerambycidae). Dusenia, Curitiba, 4: 181-228.

Recebido em 27.XI.1996; aceito em 03.XI.1997 